\title{
The Effectiveness of Febrile Neutropenia Prophylaxis with Lipegfilgrastim in Routine Clinical Practice
}

\author{
LUBOS HOLUBEC ${ }^{1,2}$, JIRI POLIVKA ${ }^{1,3,4}$, LENKA LISNEROVA ${ }^{2}$, \\ TEREZA KUBIKOVA ${ }^{1,3}$ and MARTIN SAFANDA ${ }^{2}$ \\ ${ }^{1}$ Biomedical Center, Faculty of Medicine in Plzen, Charles University, Pilsen, Czech Republic; \\ ${ }^{2}$ Department of Clinical Oncology, Na Homolce Hospital, Prague, Czech Republic; \\ ${ }^{3}$ Department of Histology and Embryology, Faculty of Medicine in Pilsen, \\ Charles University, Plzen, Czech Republic; \\ ${ }^{4}$ Department of Neurology, Faculty Hospital Plzen, Pilsen, Czech Republic
}

\begin{abstract}
Febrile neutropenia $(F N)$ is a common and potentially fatal complication of anticancer treatment, particularly in patients receiving myelosuppressive chemotherapy. It has been shown that prophylaxis with granulocyte colony-stimulating factor (G-CSF), especially its pegylated forms, significantly reduces the incidence of $F N$, the likelihood of chemotherapy dose intensity reduction and, also, the number of hospitalizations due to FN. This review discusses currently published results from clinical trials dealing with FN prophylaxis in routine clinical practice in patients with solid tumors and myeloproliferative malignancies with a focus on lipegfilgrastim, which is the newest modification of the original molecule filgrastim. The discussed results proved that prophylactic administration of lipegfilgrastim can almost eliminate the risk of $F N$ and significantly reduce the risk of chemotherapy (CHT) dose reduction in routine clinical practice in cases of a clear highrisk chemotherapy regimen or in the presence of risk factors (such as age, comorbidities, performance status, etc.) in patients who received chemotherapy with medium risk of $F N$.
\end{abstract}

The vast majority of chemotherapy (CHT) regimens used in the treatment of cancer patients is burdened with hematological

This article is freely accessible online.

Correspondence to: Jiri Polivka, Biomedical Center, Department of Histology and Embryology, Faculty of Medicine in Plzen, Charles University, Husova 3, 301 66, Plzen, Czech Republic. Tel: +420 377593320,e-mail: polivkajiri@gmail.com

Key Words: Lipegfilgrastim, myelosuppressive chemotherapy, febrile neutropenia, prophylaxis, review. toxicities that can manifest by impaired cell division of white blood cells, particularly neutrophils. Effectiveness of myelosuppressive CHT is often limited by the dose-dependent toxicity, which determines the possibility of administration of additional treatment cycles (1). The risk of infectious complications significantly increases along with the decline of granulocytes below the critical level (absolute neutrophil count $<500$ cells $/ \mathrm{mm}^{3}$ ). Severe neutropenia (grade 3 and 4), lasting for more than three days, causes a linear increase in the risk of febrile neutropenia (FN) (10\% per day). $\mathrm{FN}$ is a common and potentially fatal complication of anticancer treatment $(2,3)$. The administration of granulocyte colony-stimulating factor (G-CSF) recombinant forms results in a reduction of neutropenia and its occurrence. It has been shown that prophylaxis with G-CSF, especially its pegylated forms, significantly reduces the incidence of FN, the likelihood of chemotherapy dose intensity reduction and, also, the number of hospitalizations due to FN (4-10). Lipegfilgrastim is the newest glycopegylated modification of the original molecule filgrastim, which shows maximal structural conformity with the endogenous G-CSF. The glycopegylated form enables application of filgrastim once during the cycle of chemotherapy $(11,12)$. This review discusses several interesting results of interim analysis from non-interventional studies evaluating the safety and efficacy of lipegfilgrastim in routine clinical practice that have been recently published.

\section{The Role of Lipegfilgrastim in Routine Clinical Practice}

One of the most interesting results in FN prophylaxis comes from the recently published interim analysis of noninterventional clinical trial LEOS (a prospective pan-European non-interventional study evaluating the effectiveness of lipegfilgrastim in clinical practice for the prophylaxis of 
chemotherapy-induced neutropenia in adult patients with different tumor types) (13). LEOS is a prospective, noninterventional study that included patients with various tumor types treated with myelosuppressive, cytotoxic chemotherapy. Patients received lipegfilgrastim for primary (PP) or secondary (SP) neutropenia prophylaxis. CHT dose adjustments, the severity of neutropenia and events or complications associated with neutropenia were recorded and analyzed. Patients with various solid tumors and lymphoproliferative disorders $(n=621)$ were included into the interim analysis. Median patients' age was 59.2 years; $67.6 \%$ were women. Most patients suffered from breast cancer $(39.8 \%)$ and lymphoma (24\%). High $(>20 \%)$ and moderate risk (10-20\%) of FN were observed in $53.1 \%$ and $37.2 \%$ of patients, respectively. Prophylaxis with pegfilgrastim was, thus, administered in real clinical practice to a relatively high percentage of patients with moderate risk of FN. Lipegfilgrastim PP was initiated in $80.7 \%$ of patients and SP in $15.1 \%$ of patients. CHT dose omissions, delays or reductions in LEOS trial were very low because of the prophylaxis with lipegfilgrastim. CHT dose omissions were observed in $0.3 \%$ and $0 \%$ of patients when lipegfilgrastim was used in PP and SP, respectively. CHT dose delays were observed in $10.2 \%$ and $15.2 \%$ of patients with PP and SP, whereas dose reductions were needed in $4.8 \%$ and $7.6 \%$ of patients with PP and SP, respectively. FN was reported in $2.4 \%$ and $1.2 \%$ of patients with PP and SP, while severe neutropenia (grade 4) was reported in 2.9 and $4.8 \%$ of patients with PP and $\mathrm{SP}$, respectively. The lipegfilgrastim safety profile was very favorable. In total, $17 \%$ of patients had at least one adverse event (grade 1,2), with the most common being headache, myalgia and skeletal pain. Serious adverse events (grade 3,4 according to Common Terminology Criteria for Adverse Events (CTCAE) v4.03) occurred in only $4.8 \%$ of patients. The results of this interim analysis demonstrated the substantial effectiveness and safety of lipegfilgrastim in the primary and secondary prophylaxis of chemotherapy-induced neutropenia.

Other important results of FN prophylaxis with lipegfilgrastim came from the NADIR clinical trial (a non-interventional study on the prophylaxis of chemotherapy-induced neutropenia using lipegfilgrastim). NADIR trial was a non-interventional, prospective, multicenter study established in 2014 and carried out in 270 Germany centers. This study evaluated the effectiveness (decrease in incidence of severe neutropenia/National Cancer Institute (NCI) CTCAE grade 3, 4/or febrile neutropenia) and safety of lipegfilgrastim in patients undergoing myelosuppressive chemotherapy. Recently, there were published results from an interim analysis of NADIR clinical trial in a subset of patients with breast cancer that included 741 breast cancer patients (14). All patients had undergone chemotherapy, of which 274 had been treated with dose-dense regimens (DDR; two weeks treatment interval, comprising at least one of epirubicin, cyclophosphamide or taxanes). Patients obtained lipegfilgrastim for neutropenia PP, SP or with curative intent. Median patients' age was 53.9 years (all patients) and 51.3 years (DDR). The majority of patients was in good clinical condition with Eastern Cooperative Oncology Group (ECOG) 0/1 in 91.9\% (96.3\% for DDR). More than half of patients experienced at least one comorbidity $(50.7 \%$ of all patients, $96.3 \%$ for DDR). Most patients (89.1\% of the whole cohort, $97.1 \%$ for DDR) were treated in the neoadjuvant or adjuvant setting and $96.1 \%$ of patients received regimens comprising anthracyclines and/or taxanes. The vast majority of patients were treated with lipegfilgrastim in PP $(83.7 \%$ of all patients, $98.5 \%$ for DDR), whereas only a minority of patients were treated within the SP $(11.3 \%$ of the whole cohort, $0.4 \%$ for DDR) and with curative intent (3.8\% of all patients, $0.4 \%$ for DDR). The chemotherapy regimen with high risk ( $>20 \%)$ of $\mathrm{FN}$ was applied in $55.9 \%$ of patients (68.6\% for DDR). Interestingly a relatively high percentage of patients in moderate risk of $\mathrm{FN}$ (10-20\%) underwent prophylactic lipegfilgrastim (42.4\% of the whole cohort, $29.9 \%$ for DDR). These data indicate that the riskiness of chemotherapy regimen was not the only criterion for making clinical decision on the lipegfilgrastim application in neutropenia PP. In routine clinical practice, physicians are also taking into account additional criteria (such as patients' age, comorbidities, performance status and others). The incidence of at least one episode of FN during the observation period was detected in only $2.2 \%$ of breast cancer patients (1.8\% for DDR). From the perspective of lipegfilgrastim effectiveness, it was favorable that the CHT dose reductions due to chemotherapyinduced severe neutropenia were observed only in $0.7 \%(0.6 \%$ for DDR) of administrated CHT cycles. The lipegfilgrastim safety profile was very good in this sub-analysis as well. Adverse events associated with lipegfilgrastim administration were observed in $26.7 \%$ of patients (34.3\% for DDR). The most common adverse event was skeletal pain $(11.1 \%$ of all patients, $18.6 \%$ for DDR). Serious adverse events (grade 3, 4 - according to CTCAE V4.03) were observed in $2.6 \%$ of patients $(3.3 \%$ in DDR). Also, this interim analysis demonstrated high effectiveness and safety of lipegfilgrastim for prophylaxis of chemotherapy-induced neutropenia in the subset of patients with breast cancer.

Favorable results in FN prophylaxis with lipegfilgrastim in routine clinical practice were observed also for patients suffering from non-Hodgkin's lymphoma (NHL). Another interim analysis examined the subset of patients with NHL from the NADIR clinical trial (15). In this sub-analysis, there were evaluated 205 patients with NHL undergoing chemotherapy, of which 66 were treated with (R-)CHO(E)P-14 regimen (including at least one of cyclophosphamide, vincristine and doxorubicin). Once again, patients received lipegfilgrastim during ongoing chemotherapy treatment for neutropenia PP, SP or with curative intent. The median patients' age was 68.1 years and $78.5 \%$ of patients had at least one comorbidity. The majority of patients $(81 \%)$ had good performance status ECOG $0 / 1$. More than half $(57.1 \%)$ of patients $(69.7 \%$ for (R- 
Table I. Effectiveness and safety of lipegfilgrastim neutropenia prophylaxis in routine clinical practice. Summary of results from published interim analyses.

\begin{tabular}{lcccc}
\hline $\begin{array}{l}\text { Cancer diagnosis } \\
\text { (Clinical trial) }\end{array}$ & $\begin{array}{c}\text { Number of pts. included } \\
\text { in interim analyses }\end{array}$ & $\begin{array}{c}\text { Febrile neutropenia } \\
\text { incidence }(\%)\end{array}$ & $\begin{array}{c}\text { Severe neutropenia } \\
\text { (grade 3, 4) incidence (\%) }\end{array}$ & $\begin{array}{c}\text { Serious adverse } \\
\text { events }(\%)\end{array}$ \\
\hline $\begin{array}{l}\text { Various cancer types } \\
\text { (LEOS trial) }\end{array}$ & 621 & $2.4(\mathrm{PP})$ & 2.9 (grade 4, PP) & 4.8 \\
$\begin{array}{l}\text { Breast cancer } \\
\text { (NADIR trial) }\end{array}$ & 741 & $1.2(\mathrm{SP})$ & 2.8 (grade 4, SP) & 29.4 \\
$\begin{array}{l}\text { Non-Hodgkin's lymphoma } \\
\text { (NADIR trial) }\end{array}$ & $\begin{array}{c}\text { (of which 274 with DDR) } \\
\text { (of which 66 with (R-) }\end{array}$ & $1.8(\mathrm{DDR})$ & 33.9 (DDR) & 3.3 (DDR) \\
& CHO(E)P-14 regimen) & 2.0 & 37.1 & 0.5 \\
\end{tabular}

PP, Primary prophylaxis; SP, secondary prophylaxis; DDR, dose-dense chemotherapy regimen; pts, patients.

)CHO(E)P-14) were treated by $\mathrm{CHT}$ with curative intent (adjuvant therapy, neoadjuvant therapy), whereas $41.5 \%$ of patients $(27.3 \%$ for $(\mathrm{R}-) \mathrm{CHO}(\mathrm{E}) \mathrm{P}-14)$ were treated with palliative intent. Most patients obtained lipegfilgrastim in PP (74.1\% of the whole cohort of patients, $90.9 \%$ for (RCHO(E)P-14) and only $13.7 \%$ of patients (3\% for (R)CHO(E)P-14) were treated in SP. For the remaining patients, lipegfilgrastim was used with curative intent. Chemotherapy regimens with high risk $(>20 \%)$ of $\mathrm{FN}$ were administered in $59.5 \%$ of patients $(63.6 \%$ for $(\mathrm{R}-) \mathrm{CHO}(\mathrm{E}) \mathrm{P}-14)$. A relatively high percentage of patients in moderate risk of FN (10-20\%) again played a role in the decision-making process of lipegfilgrastim administration. Also, in myeloproliferative diseases, there exist other important cofactors in the decisionmaking process of lipegfilgrastim administration (such as comorbidities, patient's age and performance status) $(16,17)$. Severe neutropenia (NCI CTCAE grade 3,4 ) occurred in $37.1 \%$ of patients (36.4\% for (R-)CHO(E)P-14); however, at least one episode of $\mathrm{FN}$ was observed in only $2 \%$ of patients (3\% for (R)CHO(E)P-14). The necessity to CHT dose reduction was observed only in $7.1 \%$ (7.3\% for (R-)CHO(E)P-14) of administrated CHT cycles (990 cycles in all patients with NHL and 354 cycles for the $(\mathrm{R}) \mathrm{CHO}(\mathrm{E}) \mathrm{P}-14$ regimen, respectively). From the perspective of lipegfilgrastim effectiveness, it was favorable that the CHT dose reductions due to chemotherapyinduced severe neutropenia were observed only in $0.7 \%(0.3 \%$ for (R)CHO(E)P-14) of administrated cycles. The safety profile of lipegfilgrastim was once again very positive in this interim analysis. Adverse events associated with the administration of lipegfilgrastim were observed in $14.1 \%$ of patients $(6.1 \%$ for (R-)CHO(E)P-14). The skeletal pain was the most common side-effect (4.4\% of all patients, $1.5 \%$ for $(\mathrm{R}-) \mathrm{CHO}(\mathrm{E}) \mathrm{P}-14)$. Serious side-effects (grade 3, 4 - according to CTCAE V4.03) associated with the lipegfilgrastim administration were observed in $0.5 \%$ of patients $(0 \%$ for $(\mathrm{R}-) \mathrm{CHO}(\mathrm{E}) \mathrm{P}-14)$. Therefore, this interim analysis as well demonstrated the high effectiveness and safety of lipegfilgrastim for prophylaxis of chemotherapyinduced neutropenia in the subset of patients with NHL.

\section{Summary}

Based on the results discussed above, it can be summarized that lipegfilgrastim is safe and effective in the prevention of $\mathrm{FN}$ in medium, as well as high-risk CHT regimens, in patients with various diagnoses of solid tumors and lymphoproliferative disorders (Table I). Lipegfilgrastim is safe and highly effective also in patients treated with intensified regimens (DDR, (R)CHO(E)P-14) that are administered at two-week intervals. The severe neutropenia, as well as FN incidences, were very low in all published interim analyses. Lipegfilgrastim was well tolerated. The types and numbers of reported adverse events were in concordance with the XM022 registration study and the results of similar analyses $(11,18)$. It is important to realize that the risk of $\mathrm{CHT}$ regimen (in relation to $\mathrm{CHT}$-induced neutropenia) is not the only criterion of G-CSF administration in the prevention of FN. Other very important factors are patient's condition (such as age, comorbidities, performance status) and the mutual cooperation between the patient and doctor (good compliance) $(5,19,20)$. The discussed results proved that the prophylactic administration of lipegfilgrastim can almost eliminate the risk of $\mathrm{FN}$ and significantly reduce the risk of CHT dose reduction in the routine clinical practice in cases of a clear high-risk chemotherapy regimen or, in the presence of risk factors (such as age, comorbidities, performance status etc.), in patients who received chemotherapy with medium risk of FN. This finding becomes more important especially for patients in the adjuvant stage of an oncological treatment.

\section{Conflicts of Interest}

The Authors declare that they have no conflicts of interest regarding the publication of this paper.

\section{Acknowledgements}

This work was supported by the National Sustainability Program I (NPU I) Nr. LO1503 provided by the Ministry of Education Youth and Sports of the Czech Republic and by MH CZ - DRO (Faculty Hospital Plzen - FNP1, 00669806). 


\section{References}

1 Almenar CD, Bosch RC, Jiménez OE, Álvarez R, Cuervo JM, Díaz FN, Sánchez HAB, Galán B, Giner MV, Codes M, De Villena $M$ and LEARN II Study Group: Effectiveness of daily versus nondaily granulocyte colony-stimulating factors in patients with solid tumours undergoing chemotherapy: A multivariate analysis of data from current practice. Eur J Cancer Care (Engl) 22: 400-412, 2013.

2 Shayne M, Crawford J, Dale DC, Culakova E, Lyman GH and ANC Study Group: Predictors of reduced dose intensity in patients with early-stage breast cancer receiving adjuvant chemotherapy. Breast Cancer Res Treat 100: 255-262, 2006.

3 Krzemieniecki K, Sevelda P, Erdkamp F, Smakal M, Schwenkglenks M, Puertas J, Trojan A, Szabo Z, Bendall K and Maenpaa J: Neutropenia management and granulocyte colonystimulating factor use in patients with solid tumours receiving myelotoxic chemotherapy - findings from clinical practice. Support Care Cancer 22: 667-677, 2014.

4 Aapro MS, Bohlius J, Cameron DA, Dal Lago L, Donnelly JP, Kearney N, Lyman GH, Pettengell R, Tjan-Heijnen VC, Walewski J, Weber DC, Zielinski C and European Organisation for Research and Treatment of Cancer: 2010 update of EORTC guidelines for the use of granulocyte-colony stimulating factor to reduce the incidence of chemotherapy-induced febrile neutropenia in adult patients with lymphoproliferative disorders and solid tumours. Eur J Cancer Oxf Engl 1990 47: 8-32, 2011.

5 Cooper KL, Madan J, Whyte S, Stevenson MD and Akehurst RL: Granulocyte colony-stimulating factors for febrile neutropenia prophylaxis following chemotherapy: Systematic review and meta-analysis. BMC Cancer 11: 404, 2011.

6 von Minckwitz G, Schwenkglenks M, Skacel T, Lyman GH, Pousa AL, Bacon P, Easton V and Aapro MS: Febrile neutropenia and related complications in breast cancer patients receiving pegfilgrastim primary prophylaxis versus current practice neutropenia management: Results from an integrated analysis. Eur J Cancer Oxf Engl 1990 45: 608-617, 2009.

7 Naeim A, Henk HJ, Becker L, Chia V, Badre S, Li X and Deeter $\mathrm{R}$ : Pegfilgrastim prophylaxis is associated with a lower risk of hospitalization of cancer patients than filgrastim prophylaxis: A retrospective United States claims analysis of granulocyte colony-stimulating factors (G-CSF). BMC Cancer 13: 11, 2013.

8 Aapro M, Crawford $\mathrm{J}$ and Kamioner D: Prophylaxis of chemotherapy-induced febrile neutropenia with granulocyte colony-stimulating factors: Where are we now? Support Care Cancer 18: 529-541, 2010.

9 Lyman GH, Dale DC, Culakova E, Poniewierski MS, Wolff DA, Kuderer NM, Huang $M$ and Crawford J: The impact of the granulocyte colony-stimulating factor on chemotherapy dose intensity and cancer survival: a systematic review and meta-analysis of randomized controlled trials. Ann Oncol 24: 2475-2484, 2013.

10 Younis T, Rayson D, Jovanovic S and Skedgel C: Costeffectiveness of febrile neutropenia prevention with primary versus secondary G-CSF prophylaxis for adjuvant chemotherapy in breast cancer: A systematic review. Breast Cancer Res Treat 159: 425-432, 2016.

11 Bondarenko I, Gladkov OA, Elsaesser R, Buchner A and Bias P: Efficacy and safety of lipegfilgrastim versus pegfilgrastim: A randomized, multicenter, active-control phase 3 trial in patients with breast cancer receiving doxorubicin/docetaxel chemotherapy. BMC Cancer 13: 386, 2013.
12 Gladkov OA, Buchner A, Bias P, Müller U and Elsässer R: Chemotherapy-associated treatment burden in breast cancer patients receiving lipegfilgrastim or pegfilgrastim: Secondary efficacy data from a phase III study. Support Care 24: 395-400, 2016.

13 Pichler P, Claes N, Mazza P, Zurawski B, Potocki P, Petru E, Šedivá M, Katolicka J, Lanza F and Fontaine C: Use of lipegfilgrastim in clinical practice for the prophylaxis of chemotherapy-induced neutropenia: Interim results of pan-European non-interventional study. Ann Oncol 27(Suppl 6): 1459P, 2016.

14 Kurbacher CM, Fietz T, Trarbach T, Salat C, Rezai M, Lorenz $A$ and Niemeier B: Prophylaxis of chemotherapy-induced neutropenia with lipegfilgrastim in patients with breast cancer: Results from an interim analysis of the non-interventional study NADIR. Ann Oncol 27(Suppl 6): 1457P, 2016.

15 Fietz T, Wolff T, Schulz H, Sandner R, Reichert D, Hurtz J, Müller J and Grebhardt S: Prophylaxis of chemotherapy-induced neutropenia with lipegfilgrastim in patients with non-Hodgkin lymphoma (NHL): Results from an interim analysis of the noninterventional study NADIR. DGHO Jahrestagung 2016, Leipzig, Germany, Poster P950, 2016.

16 Lee S, Knox A, Zeng ISL, Coomarasamy C, Blacklock H and Issa $\mathrm{S}$ : Primary prophylaxis with granulocyte colony-stimulating factor (GCSF) reduces the incidence of febrile neutropenia in patients with non-Hodgkin lymphoma (NHL) receiving CHOP chemotherapy treatment without adversely affecting their quality of life: Cost-benefit and quality of life analysis. Support Care Cancer 21: 841-846, 2013.

17 Pettengell R, Bosly A, Szucs TD, Jackisch C, Leonard R, Paridaens R, Constenla M, Schwenkglenks $M$ and Impact of Neutropenia in Chemotherapy-European Study Group (INCEU): Multivariate analysis of febrile neutropenia occurrence in patients with non-Hodgkin lymphoma: Data from the INC-EU Prospective Observational European Neutropenia Study. Br J Haematol 144: 677-685, 2009.

18 Guariglia R, Martorelli MC, Lerose R, Telesca D, Milella MR and Musto P: Lipegfilgrastim in the management of chemotherapy-induced neutropenia of cancer patients. Biol Targets Ther 10: 1-8, 2016.

19 Altwairgi AK, Hopman WM and Mates M: Real-world impact of granulocyte-colony stimulating factor on febrile neutropenia. Curr Oncol Tor Ont 20: e171-179, 2013.

20 Wang L, Baser O, Kutikova L, Page JH and Barron R: The impact of primary prophylaxis with granulocyte colonystimulating factors on febrile neutropenia during chemotherapy: A systematic review and meta-analysis of randomized controlled trials. Support Care Cancer 23: 3131-3140, 2015. 